\title{
Study on Soldering Technology for Laser Rod by Finite Element Method
}

Hao ming-ming

Science and Technology on Reliability Physics and Application of Electronic Component

Laboratory

China Electronic Product Reliability and Environmental Testing Research Institute

Guangzhou, china

ciomp2007@163.com

Lu guo-guang, Lei zhi-feng, Huang Yun, En Yunfei

Science and Technology on Reliability Physics and Application of Electronic Component

Laboratory

China Electronic Product Reliability and Environmental Testing Research Institute

Guangzhou, china

\begin{abstract}
With the increase demand of high power, high efficient and good beam quality solidstate lasers, thermal management become more important for the lasers. Thermal resistance between laser crystal and heat sink can be effectively reduced by soldering technology, but the technology might induce huge heat stress. In order to solve the problem, finite-element method was used to analysis the stress and thermal resistance. Moreover, a practicable structure was also designed and calculated in this study.
\end{abstract}

Keywords-lasers crystal rod; thermal stress; thermal resistance; Soldering technology

\section{INTRODUCTION}

In recent years, laser diode-(LD)-pumped solid-state lasers have attracted great attention owing to the excellent properties, such as high efficiency, simplicity, compactness, and good frequency stability, of the lasers [1]. But the lasers especially for high power operation mode will generate large number of heat during its working because of quantum defect, mismatch between material's absorption wavelength and pumping wavelength and so on, which could essentially influence the working character of the lasers [2]. On the one hand, thermal effects might induce stress fracture and reduced the reliability of the lasers; on the other hand thermal lens induced by thermal effects decrease beam quality of the lasers [3].

Presently, mounting laser rod by mechanically clamping is a mostly used method. In order to decrease contact thermal consistence, material such as indium foil, graphite layer and heat sink grease should be applied. It is reported that heat transfer coefficient of $h=60$ $\mathrm{W} /\left(\mathrm{m}^{2} \cdot \mathrm{K}\right)$ for indium-wrapped crystals, $\mathrm{h}=28 \mathrm{~W} /\left(\mathrm{m}^{2} \cdot \mathrm{K}\right)$ when using graphite layer and 
$\mathrm{h}=200 \mathrm{~W} /\left(\mathrm{m}^{2} \cdot \mathrm{K}\right)$ when using heat sink grease [4-5]. Therefore heat sink grease could effectively decrease contact thermal consistence, but the grease tend to volatilize and decompose to air which reduce the reliability of the lasers.

In order to solve the problem, soldering technology was studied by finite-element method to optimizing the material and structure of the thermal manage for laser crystal rod.

\section{COMPUTATION OF HEAT INDUCED STRESS DURING SODERING BY FINITE- ELEMENT}

\section{A. Finite element modeling}

The process of soldering laser rod and heat sink can be described as follows. Firstly, laser rod should be coated with solder alloy; Secondly, laser rod should be mechanically clamped in the hole of the heat sink and heated in the ambient of shielding air until the solder alloy melting; finally, the laser rod and heat sink should be slowly cooled and the structure can be shown as figure 1 .

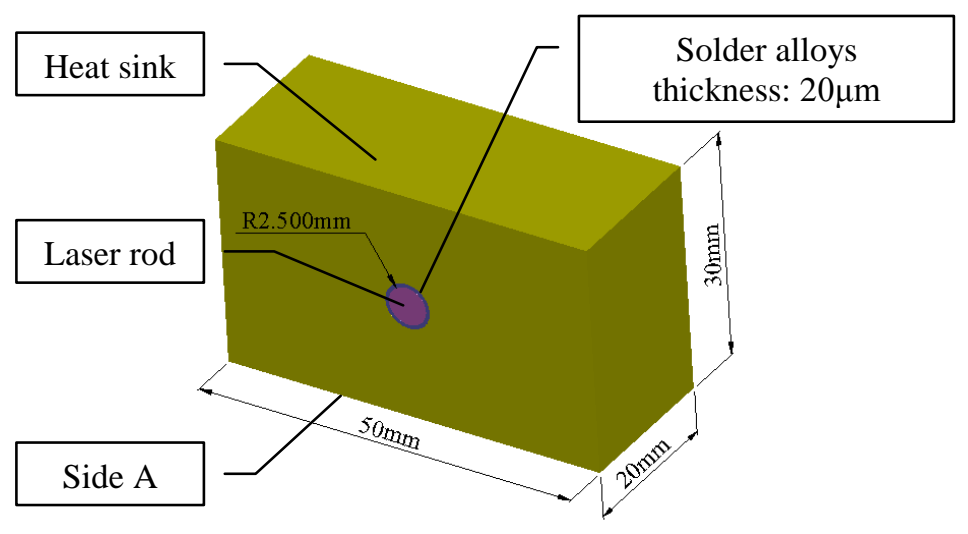

Fig1. Structure of the model after soldering

In order to creating finite-element model in COMSOL multiphysics software according to Fig1, physic of thermal stress was chosen. The problem should be study with time dependent because the thermal stress had generated during the process of anneal. Finally, the structure should be meshed to form finite-element model and can be calculated by computer.

\section{B. Residue stress and Melting point of solder alloys}

Melting Point of the solder alloys was set as strain reference temperature in COMSOL software while kept other value constant. It is assumed that the material of the heat sink was copper and the laser rod is Nd:YAG. The physical and mechanical properties of these materials can be shown as table I . Heat transfer on side A can be seen convective cooling 
and the heat transfer coefficient is assumed $5000 \mathrm{~W} /\left(\mathrm{m}^{2} \cdot \mathrm{K}\right)$ while the ambient temperature set as $20^{\circ} \mathrm{C}$.

TABLE I. PHYSICAL PROPERTIES OF THE MATERIAL

\begin{tabular}{|c|c|c|c|}
\hline Physical properties & Copper & Nd:YAG & Solder Alloys \\
\hline $\begin{array}{c}\text { Coefficient of thermal } \\
\text { expansion }\left[\mathrm{K}^{-1}\right]\end{array}$ & $17 \times 10^{-6}$ & $6.9 \times 10^{-6}$ & $3.2 \times 10^{-5}$ \\
\hline $\begin{array}{c}\text { Specific Heat } \\
\text { Capacity [J/(Kg:K)] }\end{array}$ & 385 & 590 & 233 \\
\hline $\begin{array}{c}\text { Thermal Conductivity } \\
{[\mathrm{K} /(\mathrm{W} \cdot \mathrm{m})]}\end{array}$ & 400 & 13 & 81.8 \\
\hline $\begin{array}{c}\text { Modulus of Elasticity } \\
{[\mathrm{GPa}]}\end{array}$ & 110 & 310 & 11 \\
\hline $\begin{array}{c}\left.\text { Density [Kg/m }{ }^{3}\right] \\
\text { Poisson ratio }\end{array}$ & 0.35 & 0.3 & 0.45 \\
\hline
\end{tabular}

At the beginning of the research, the solder alloys is assumed as indium, so the strain reference temperature should set $156.6^{\circ} \mathrm{C}$. After the computing, the distribution of Von mission stress can be shown as figure 2. From the figure we can see that the maximum Von mission stress can reach to $306 \mathrm{MPa}$ and the position locate at surface of the laser rod.

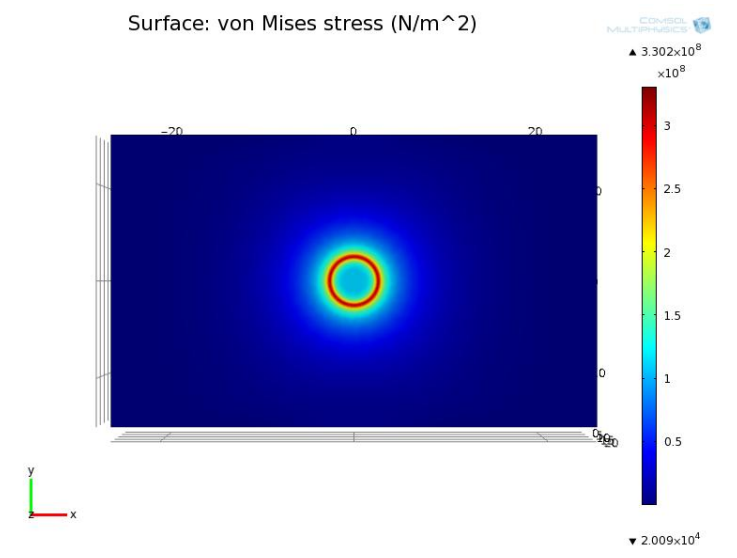

Fig2. Residual stress of the model during temperature drop

Secondly, melting point of solder alloys was changed in the software while keeping other parameters constant. After calculation, the relationship between the melting point and residual stress can be acquired and was drawn in figure 3 . As can be seen from the figure, the residual stress linear increase with the adding melting point, and the incremental ratio is $2.3 \mathrm{MPa} /{ }^{\circ} \mathrm{C}$. 


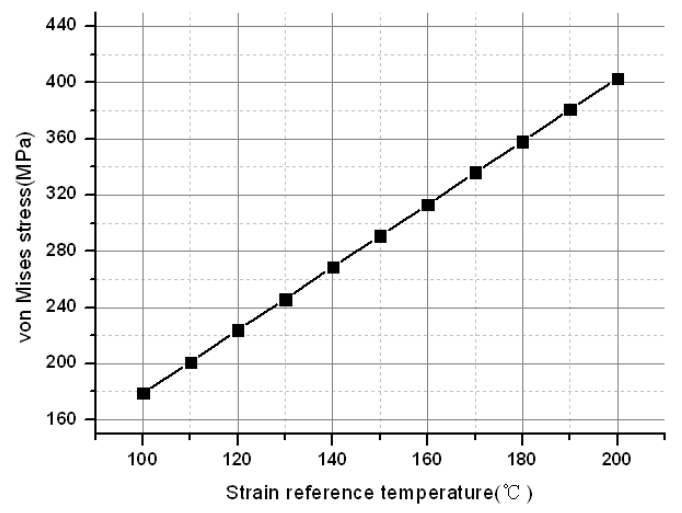

Fig3. Residual stress varies directly with the melting point of solder alloys

Therefore, applying low melting point solder alloys such as alloys of tin (Sn) and lead $(\mathrm{Pb})$ with or without silver $(\mathrm{Ag})$ with or without indium (In) whose melting point lower than $200^{\circ} \mathrm{C}$ could effectively reduce residual stress.

\section{Physical properties of heat sinks}

Finally, coefficient of thermal expansion (CTE) of heat sink was changed to computing residual stress of the heat sink while keeping other parameter constant. Figure 3 was drawn according to the computing result. From the figure we can see that with the CTE of heat sink material increasing from $1.0 \times 10^{-6} \mathrm{~K}^{-1}$ to $2 \times 10^{-5} \mathrm{~K}^{-1}$, the maximum residual stress of laser rod firstly reduce till CTE of heat sink material equal to laser crystal but the residual stress increase after that point. So the residual stress is depended on differential value of CTE between heat sink and laser material.

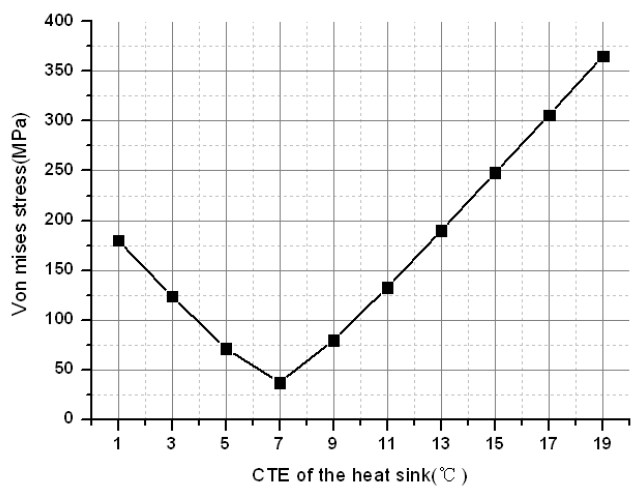

Fig4. Relationship between maximum von mises stress of laser rod and CTE of heat sink 


\section{Thermal PERFORMANCE}

A important parameter for the model is thermal resistance $\left(R_{\mathrm{th}}\right)$ which can be defined as the increase temperature $(T)$ of the laser rod per incremental Watt of waste heat $(Q)$ :

$$
R_{t h}=\frac{d T}{d Q}
$$

In order to compute the thermal resistance of the laser model, it is firstly required to calculate the temperature field at any point of the crystal. One has to solve the heat equation:

$$
\rho C_{p} \frac{\partial T(x, y, z, t)}{\partial t}-K_{c} \nabla^{2} T(x, y, z, t)=q_{v}(x, y, z, t)
$$

with :

$T(x, y, z, t)$ : temperature in $\mathrm{K}$;

$\rho:$ density in $\mathrm{kg} \cdot \mathrm{m}^{-3}$;

$C_{p}$ : specific heat in $\mathrm{J} \mathrm{kg}^{-1} \cdot \mathrm{K}^{-1}$;

$K \mathrm{c}:$ thermal conductivity in $\mathrm{W} \cdot \mathrm{m}^{-1} \cdot \mathrm{K}^{-1}$;

$q_{v}(x, y, z, t)$ : thermal power (or thermal load) per unit volume in $\mathrm{W} \cdot \mathrm{m}^{-3}$.

It is assumed that the pumping laser can be seen as Gauss distribution, so the function of heat generation $q_{v}(r, z)$ can be written as:

$q_{v}(r, z)=\frac{2 \alpha \eta P_{i n}}{\pi \omega_{P}^{2}(1-\exp (-\alpha L))} \exp \left[-2\left(r^{2} / \omega_{P}^{2}\right)-\alpha z\right]$ (3) Where:

- $\alpha$ is the absorption coefficient of laser rod;

- $\eta$ is fractional thermal load;

- $P_{\text {in }}$ is the incident optical pump power;

- $\omega_{P}$ is the waist radius of pump laser beam;

- $L$ is length of laser rod.

In the computation, it is assumed that $\alpha=300 \mathrm{~m}^{-1}, \quad \eta=0.43, \quad P_{\mathrm{in}}=50 \mathrm{~W}$,

$\omega_{P}=400 \mu \mathrm{m}, L=20 \mathrm{~mm}$. Setting equation 3 to COMSOL multiphysics and applying stationary solver, temperature distribution of the laser rod was acquired and shown in figure 5. From the figure we can see that the maximum temperature reaching to $184.4^{\circ} \mathrm{C}$ locate at the centre of the laser rod. 


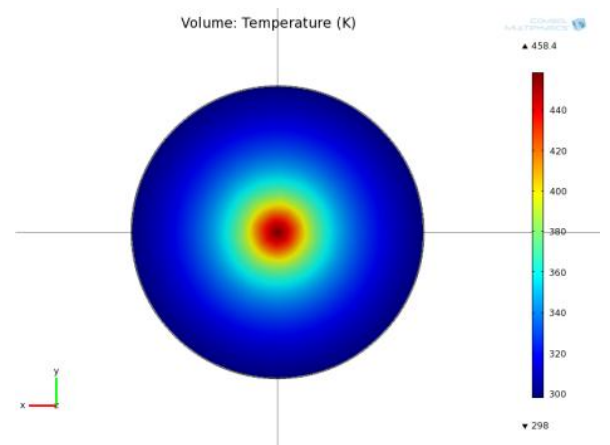

Fig5. Temperature distribution of the laser rod

According to equation 1, thermal resistance can be computed with COMSOL. From figure 6 we can see that the thermal resistance is inversely proportion to the thermal conductive of the heat sink material. When the thermal conductive of the heat sink material is high than that of the heat sink, the thermal resistance of the model changes inconspicuously.

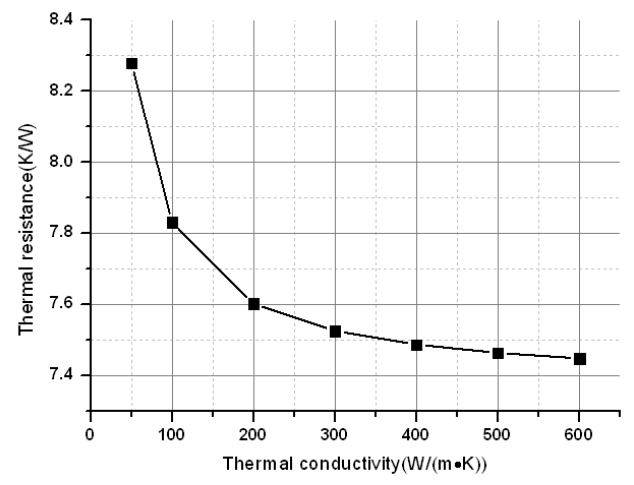

Fig6. Relationship between heat sink material and the thermal resistance

\section{VIABLE STRUCTURE FOR COOLING LASER ROD}

In order to design a practicable mounting structure for laser rod, performance of the system were researched with different heat sink material by finite-element method. Firstly, the parameters of Pd50In50 which is a low melting point solder alloys was set in COMSOL software as table II. 
TABLE II. PHYSICAL PROPERTIES OF PD50IN50

\begin{tabular}{|c|c|}
\hline Physical and mechanical properties & Pb50In50 \\
\hline Coefficient of thermal expansion $\left[\mathrm{K}^{-1}\right]$ & $2.60 \mathrm{E}-5+1.71 \mathrm{E}-8 \times \mathrm{T}$ \\
\hline Specific Heat Capacity $[\mathrm{J} /(\mathrm{Kg} \cdot \mathrm{K})]$ & $165+0.0691 \times \mathrm{T}$ \\
\hline Thermal Conductivity $[\mathrm{K} /(\mathrm{W} \cdot \mathrm{m})]$ & 50 \\
\hline Modulus of Elasticity $[\mathrm{GPa}]$ & $4.14 \mathrm{E} 10-6.33 \mathrm{E} 7 \times \mathrm{T}-3.00 \mathrm{E} 4 \times \mathrm{T}^{2}$ \\
\hline Density $\left[\mathrm{Kg} / \mathrm{m}^{3}\right]$ & $9.06 \mathrm{E} 3-0.572 \times \mathrm{T}-4.29 \mathrm{E}-4 \times \mathrm{T}^{2}$ \\
\hline Poisson ratio & 0.33 \\
\hline
\end{tabular}

According to the conclusion $\mathrm{C}$ of section II, the residual stress depends on the CTE mismatch between laser material and heat sink, so Molybdenum Copper parts and AlSiC Metal Matrix Composite were chosen in the study. Physical and mechanical properties of these materials were listed as table2.

TABLE III. PHYSICAL PROPERTIES OF HEAT SINK MATERIALS

\begin{tabular}{|c|c|c|c|}
\hline Physical properties & Copper & Mo85Cu15 & AlSiC \\
\hline $\begin{array}{c}\text { Coefficient of thermal } \\
\text { expansion }\left[\mathrm{K}^{-1}\right]\end{array}$ & $17 \times 10^{-6}$ & $6.5 \times 10^{-6}$ & $7.0 \times 10^{-6}$ \\
\hline $\begin{array}{c}\text { Specific Heat } \\
\text { Capacity [J/(Kg } \cdot \mathrm{K})]\end{array}$ & 385 & 260 & 760 \\
\hline $\begin{array}{c}\text { Thermal Conductivity } \\
[\mathrm{K} / \mathrm{W} \cdot \mathrm{m})]\end{array}$ & 400 & 140 & 175 \\
\hline $\begin{array}{c}\text { Modulus of Elasticity } \\
{[\mathrm{GPa}]}\end{array}$ & 110 & 248 & 230 \\
\hline Density [Kg/m $\left.{ }^{3}\right]$ & 8700 & 9920 & 3040 \\
\hline Poisson ratio & 0.35 & 0.33 & 0.33 \\
\hline
\end{tabular}

As can be seen from figure 7, copper heat sink would induce highest residual stress while lowest thermal resistance; AlCSi Metal Matrix Composite heat sink would generate lowest thermal resistance; Molybdenum Copper parts heat sink would induce highest thermal resistance. 


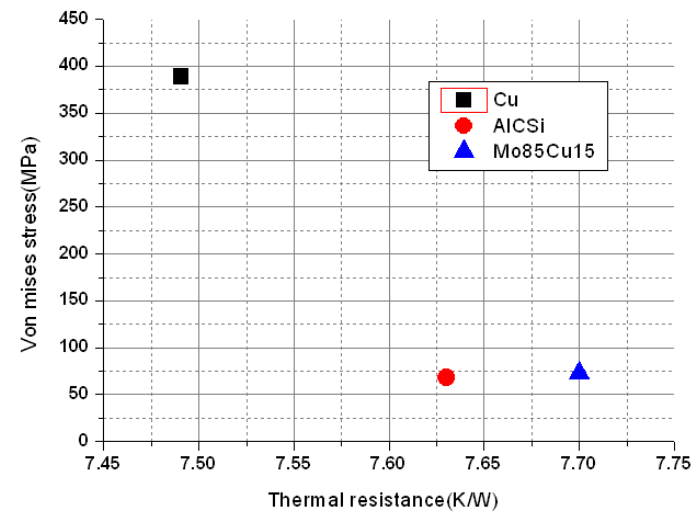

Fig7. Thermal stress and residual stress for different heat sink materials

\section{SUMMARY}

Soldering technology is important for laser rod mounting. The paper studies the physical and mechanical properties of different materials for solder alloys and heat sinks by finite-element method. Finally, we found that solder alloys should be chosen low melting point materials and AlCSi Metal Matrix Composite would be a potential material applied for heat sinks. The result would helpful to enhance the reliability of solid-state lasers.

\section{ACKNOWLEDGMENT}

The author would like to thank advanced engineer Huang Yun and En Yunfei for their discussions and encouragement.

[1] Huaijin Zhang, Junhai Liu, Jiyang Wang, Changqing Wang, Li Zhu, Zongshu Shao, Xianlin Meng, Xiaobo $\mathrm{Hu}$, and Minhua Jiang, "Characterization of the laser crystal Nd:GdVO ${ }_{4}$," J. Opt. Soc. Am. B, vol. 19, pp. 18-27, 2002.

[2] LePing Zhou, and DaWei Tang, "A functional graded structure design of mirrors for reducing their thermal deformations in high-power laser systems by finit element method," Optical \& Laser technology, vol. 39, pp. 980-986, 2007

[3] Masaki Tsunekane, Noboru Taguchi, Tadashi Kasamatsu, and Humio Inaba, "Analytical and Experimental Studies on the Characteristics of Composite Solid-State Laser Rods in Diode-End Pumped Geometry," Quantum Electronics, vol. 3, pp. 9-18, 1997.

[4] Sébastien Chénais, Frédéric Druon, Sébastien Forget1, François Balembois and Patrick Georges, "On thermal effect in solid state lasers: the case of ytterbium-doped materials," Quantum Electron, vol. 30, pp. 1-115, 2006.

[5] W. Koechner, Solid-State Laser Engineering. Round Hill, VA: Springer, 2006. 